\title{
O DESENVOLVIMENTO DA CONSCIÊNCIA HUMANA SEGUNDO A CONCEPÇÃO DO MATERIALISMO HISTÓRICO
}

\author{
THE DEVELOPMENT OF HUMAN CONSCIOUSNESS \\ ACCORDING TO HISTORICAL MATERIALISM
}

\author{
${ }^{1}$ JOAO JUNIOR BONFIM JOIA PEREIRA
}

\begin{abstract}
RESUMO
Este texto apresenta um estudo sobre o desenvolvimento da consciência do homem e seu objetivo é mostrar o que os teóricos que seguem a linha do Materialismo Histórico cunharam sobre o desenvolvimento da consciência e seus aspectos relevantes. Esse interesse apresentou-se a partir do momento em que constatamos que essa compreensão se faz necessária para a realização de uma educação escolar que esteja ciente de seu papel social. Por isso, organizamos o texto de maneira que esclareça que a consciência humana ocorre por meio da interação social e que a educação e o trabalho são fatores importantes para o seu desenvolvimento.
\end{abstract}

Palavras-chave: Consciência. Trabalho. Educação.

\begin{abstract}
This text presents a study on the development of man's consciousness. The goal of the article is to show what theoreticians associated with Historical Materialism have coined on the development of consciousness and the relevant aspects of the concept. The interest on the topic emerged from the perception that this understanding is necessary for the implementation a school education aware of its social role. Therefore, the organization of the text aims to illustrate that the human consciousness occurs through social interaction and that education and work are important factors for its development.
\end{abstract}

Keywords: Consciousness. Work. Education.

\section{Introdução}

Como professores da rede municipal de ensino, temos constatado que muitos profissionais da educação não possuem conhecimento sobre qual é papel social da educação, muito menos percebem que o homem é um ser social que se desenvolve a partir de interações sociais. Dessa forma, o ensino tem se tornado uma prática alienadora, em que os profissionais da educação não atentam para o desenvolvimento da consciência do indivíduo. Essas constatações têm-nos provocado algumas inquietações, e por isso nos questionamos o que vem acontecendo com os profissionais da educação que não levam

* Pedagogo pela UNESPAR FAFIPA. Especialização Interdisciplinar em Ciências Humanas. Professor da rede Municipal de Alto Paraná. E-mail: jjbj16@hotmail.com 
em consideração o papel social da educação. Como resolver esses problemas? Para responder a esses questionamentos apresentamos duas hipóteses: 1) que esses profissionais da educação desconhecem o modo como se desenvolve a consciência no homem; 2) que o desconhecimento sobre o desenvolvimento da consciência impossibilita que os profissionais percebam como o trabalho pode influenciá-lo; c) o papel da educação enquanto responsável pela formação de cidadãos críticos e participativos. É nesse sentido que este estudo propõe-se a apresentar o que os autores que seguem a concepção do Materialismo Histórico evidenciaram sobre o desenvolvimento da consciência.

Para atender o aqui proposto, este trabalho foi organizado em três momentos: no primeiro momento apresentaremos o desenvolvimento da consciência do homem sobre a teoria do materialismo histórico, visto que a sua compreensão é fundamental para o estudo dos itens a seguir. No segundo momento trataremos do papel do trabalho para o desenvolvimento da consciência; e no terceiro momento abordaremos as contribuições da educação para o desenvolvimento da consciência, buscando nos pressupostos teóricos do marxismo os princípios para pensar uma educação voltada para a classe trabalhadora.

\section{O desenvolvimento da consciência do homem}

Os teóricos que antecederam Marx já levavam em consideração a função do cérebro humano, que é pensar, extinguindo assim a visão sobrenatural da consciência humana; no entanto, somente Marx foi capaz de perceber que a consciência humana vai muito além das condições naturais ou biológicas. Assim, para compreender a natureza da consciência humana é necessário levar em consideração o âmbito social, ou seja, a consciência tem um caráter social.

Nas palavras de Spirkinne e Yakhot (1975, p.59):

Os materialistas anteriores a Marx sabiam já que o cérebro pensa. Sabiam igualmente que a consciência apareceu como um processo natural, que nada tinha de sobrenatural. Foi este o grande mérito do materialismo pré-marxista. Mas o Marxismo foi bastante mais longe. Falou que não se podia explicar a origem nem a natureza da consciência humana somente pelas condições naturais, biológicas. Pela primeira vez na história da ciência, o marxismo demonstrou que não se podia compreender a natureza da consciência se não se tivesse em conta o seu caráter social.

Assim, Spirkinne e Yakhot (1995) consideram que, para Marx, a vida social dos homens tem um papel fundamental na formação de sua consciência, ou seja, um indivíduo somente será capaz de desenvolver sua consciência se estiver integrado a um meio social. Luria (2006) também discorreu sobre o desenvolvimento da consciência humana. Assim como Marx, ele acredita que a consciência do homem se desenvolve por meio do convívio social e que ela nunca surgiu do nada, logo ela não se desenvolve de maneira biológica, mas sim a partir da convivência com outros indivíduos. Ela surge "[...] em suas relações com o meio circundante" (LURIA, 2006, p.194).

Para confirmar o pensamento de que a consciência se desenvolve de acordo com o meio social, Spirkinne e Yakhot (1995) tomam como exemplo as irmãs Amala e Kamala, que foram criadas entre lobos e, quando encontradas, tinham atitudes de feras, ou seja, desenvolveram características de animais. Podemos constatar, portanto, que a consciência não se desenvolve biologicamente, pois as meninas não desenvolveram uma consciência humana. Leontiev (1978) considerou que, para Vigotski, os processos psicológicos do indivíduo surgem a partir de sua interiorização de comportamentos vivenciados em seu meio social.

[...] o principal mecanismo do desenvolvimento psíquico no homem é o mecanismo de apropriação das diferentes espécies e formas sociais de atividade, historicamente construídas. (LEONTIEV, 1978, p.166).

Em outras palavras, cada indivíduo se desenvolve a partir de seu convívio social. No caso das irmãs, elas interiorizaram o comportamento dos lobos e não o de seres humanos; logo, não desenvolveram a consciência humana porque não tiveram contato com homens.

Segundo Lênin (1979), Hegel dizia que o pensamento é responsável pela criação da realidade. Contrariamente a isso, Marx dizia que o pensamento 
é reflexo do mundo real, portanto, o pensamento do homem esta ligado àquilo que ele vive ou presencia. Assim, o homem também é um produto da natureza, pois, na medida em que ele transforma a natureza, também modifica sua forma de pensar e agir com relação ao mundo. Sobre a evolução do pensamento, Luria (2006) diz que à medida que a vida e a interação com o meio se tornam mais complexas, também modificam as estruturas do organismo, consequentemente, a consciência do homem modifica-se para ficar em conformidade com o meio em que ele está inserido.

Para Spirkinne e Yakhot (1995), o desenvolvimento da consciência humana vai além do biológico e do natural; ela só ocorre quando ligada a condições sociais. Fora do convívio social o homem não desenvolve seu pensamento com características humanas. Ambos, pensamento e consciência humana, foram criados por meio do trabalho do homem para transformar a natureza e, a partir disso, transformar-se. Para Spirkinne e Yakhot (1995), juntamente com o trabalho o homem teria criado, consequentemente, sua consciência.

De acordo com os mesmos autores, com o desenvolvimento do pensamento por meio do trabalho, surgiu a necessidade de concretizar esse pensamento. Para Marx, a fala é a realidade do pensamento e, quando pensamos, mesmo que não divulguemos o pensamento a outros, ainda assim utilizamos a linguagem para nós mesmos. Dessa forma, Luria (2006) considera que a fala serve como instrumento para a organização dos comportamentos e carrega em si conceitos generalizados, os quais são fontes de conhecimento. Com isso, Spirkinne e Yakhot (1995) consideram que desde muito pequenas as crianças têm contato com a linguagem e que a mesma ajuda o homem exprimir seus desejos e pensamentos.

Spirkinne e Yakhot (1995) consideram que nenhuma máquina jamais será capaz de substituir o cérebro humano, pois o mesmo é complexo e se desenvolve por meio das relações sociais, logo, nenhuma máquina será capaz de se desenvolver mais do que o cérebro humano devido ao caráter social deste último, ou seja, as máquinas não têm o potencial de pensar e apenas facilitam a realização de determinadas tarefas. As máquinas não são capazes de desenvolver a consciência, pois as mesmas não abstraem a realidade e não avaliam as informações de maneira crítica. Sobre isso, Luria afirma que:
[...] a consciência é a habilidade em avaliar as informações sensórias, em responder a elas com o pensamento e ações críticas e em reter traços de memória de forma que traços ou ações passadas possam ser usados no futuro. (LURIA, 2006 p.196).

Para Marx e Engels (1846) a vida não é determinada pela consciência, mas sim determina a consciência. Para eles é exatamente a consciência que diferencia o homem dos outros animais, pois ela nos permite agir e transformar a natureza de maneira a suprir as necessidades que vão surgindo.

\section{O Trabalho e o desenvolvimento da consciência}

De acordo com Marx e Engels (1846), o homem é um ser histórico que se desenvolve por meio da interação social com outro de sua espécie. A partir disso ele se apropria dos meios de produção material para suprir suas necessidades. Partindo do que adquiriram no convívio social, os seres são capazes de desenvolver novas técnicas de produção material, de maneira a suprir necessidades que vão surgindo. Portanto, Marx e Engels (1846) acreditam que, para compreender o desenvolvimento da consciência, faz-se necessário buscar compreender os meios de produção material e o convívio social dos indivíduos de determinado grupo social.

Segundo Lênin (1979), os homens entram em relações sociais sem levar em consideração sua vontade - são relações de produção material. Esses meios de produção material influenciam diretamente o modo de vida social, política e economicacamente, consequentemente essa divisão influencia a formação da consciência do homem. Assim, Lênin (1979 p.22) afirma que "O modo de produção da vida material condiciona em geral o processo da vida social, política e intelectual".

Rego (1995) afirma que, para Marx, o produto de sua atividade, ou seja, o resultado final de seu trabalho, já existe muito antes de ser produzido, na mente do sujeito, o que considera o potencial humano de planejar suas ações antes mesmo de desenvolvê-las. Para ela, Marx considera o trabalho como uma atividade prática e consciente, sendo que por meio dele se desvenda o caráter social do ser humano. Sendo o trabalho um modo de formação da consciência, o trabalho desenvolvido no seio da 
sociedade capitalista é formador de homens cuja consciência é alienada, fazendo-se, assim, manter as formas de organização e divisão do trabalho de forma incorreta, onde o capitalista explora a força de produção dos trabalhadores e, no final, fica com a maior parte dos lucros do que foi produzido.

Para Marx (1849), a força de trabalho do assalariado se torna uma mercadoria para o capitalista, que a compra por um dia, uma semana ou um mês. Com isso, o capitalista utiliza a força de trabalho dos assalariados para a produção de materiais que ele venderá com o objetivo de obter lucros. Nessa relação, o assalariado vende sua mercadoria (força de trabalho) em troca de outra mercadoria (dinheiro), e o que recebe muitas vezes é menor do que o que vale. Nesse sentido, o trabalho é uma atividade vital para o homem, pois o ser humano precisa transformar a natureza por meio das forças de produção para assim suprir suas necessidades. Também por meio da venda de sua força de trabalho o operário ganha dinheiro para sobreviver.

Para Marx, os meios de produção material desenvolvidos pelos capitalistas resultaram na diminuição da taxa de mortalidade infantil. No entanto, esse tipo de produção resultou em um exército de desempregados. Lênin (1979 p.36-7) considera que:

Em regime capitalista, uma grande parte dos operários não encontra onde empregar as suas forças e constitui o exército de reserva industrial, quer dizer um exército de desempregados, engrossado ainda pelos pequenos produtores arruinados.

As classes dominantes procuram manter o poder; quando os operários - que nessa relação são os dominados - tentam mudar as relações de produção, o capitalista procura defender os meios de produção de maneira a se manter com o poder econômico e social. Os operários, nessa situação, veem-se coagidos a continuar trabalhando mesmo que sejam explorados, pois se consideram dependentes do emprego que o capitalista lhes oferece. Desta forma, o trabalho no sistema capitalista se torna alienante, de maneira que visa manter o poder econômico nas mãos de poucos e os operários não são capazes de lutar para que ocorra a mudança, pois sempre que buscam por melhorias o sistema o faz sentir-se coagidos e dependentes dele.

\section{As contribuições da educação para o de- senvolvimento da consciência}

Considerando que a consciência do homem se desenvolve por meio do convívio social com outros, a escola é um espaço que propicia a socialização entre os indivíduos, bem como a apropriação do conhecimento historicamente produzido pelos homens por meio do trabalho. Assim, na escola o indivíduo terá contato com diferentes aspectos culturais e conhecimentos, possibilitando o desenvolvimento da consciência. Sobre isso, Duarte afirma que

[...] Os indivíduos não realizam a homogeneização de forma espontânea e natural, mas sim porque assimilam, através da educação escolar, as formas de pensar e agir necessárias a esse processo. (DUARTE, 2007, p.66).

De acordo com Saviani (2005), o objetivo da prática educativa é que o aluno compreenda o saber historicamente produzido, visto que o homem não nasce sabendo e se torna homem conforme se apropria do que foi produzido pelas gerações que o antecederam. Nas próprias palavras do autor,

[...] O homem não se faz homem naturalmente; ele não nasce sabendo ser homem, vale dizer, ele não nasce sabendo sentir, pensar, avaliar, agir. Para saber pensar e agir; para saber querer, agir ou avaliar é preciso aprender, o que implica o trabalho educativo (SAVIANI, 2005 p.7).

Nesta passagem podemos perceber que a educação tem papel fundamental para o desenvolvimento dos indivíduos, logo ela é responsável pela formação social dos mesmos e, consequentemente, responsável pelo desenvolvimento da consciência deles. Rego (1995) pontua que, para Vigotski, a escola tem um papel insubstituível na formação do indivíduo, pois a mesma propicia aos alunos a análise de elementos da realidade, e, como foi visto anteriormente, a consciência do homem se forma a partir daquilo que ele presencia em seu meio social.

Como Marx, Saviani (2005) considera que o homem age sobre a natureza e a transforma, por meio do trabalho, para garantir sua sobrevivência. Partindo dessa visão, a educação é uma exigência do processo de trabalho e ao mesmo tempo ela é um processo de trabalho. De acordo com Rego (2005), na medida em que o aluno aprende, ele se desenvolve em um processo gradativo. 
Mészáros (2005) aponta que, para Marx, o homem é um produto das circunstâncias e da educação, ou seja, a educação, assim como os outros ambientes sociais, propicia a formação da consciência. No entanto, a educação tem o dever de propiciar uma formação que leve ao desenvolvimento intelectual do indivíduo, de maneira que ele possa agir conscientemente no meio em que vive, lutando para transformar sua realidade social. Por isso Saviani (2005) pontuou que, nesse contexto, a escola assume o papel de oferecer subsídios para que o indivíduo seja capaz de agir ativamente na sociedade em que está inserido, sendo capaz de transformá-la. Desta forma, a escola estará contribuindo para a transformação social por meio da formação de um ser consciente e crítico.

\section{Considerações finais}

Com o trabalho desenvolvido, constatamos que o homem é um ser social que se desenvolve a partir da interação com os outros; assim, sua consciência se forma com a interação social, bem como tudo em si se desenvolve a partir do convívio social. A consciência se desenvolve a partir da realidade e não a realidade a partir da consciência. $O$ homem vivencia situações e integra as suas estruturas cognitivas, o que resulta em seu desenvolvimento psíquico, bem como no de sua consciência.

No decorrer de sua história, o homem transforma a natureza, e, na medida em que faz isso ele modifica as relações sociais com os outros indivíduos. Consequentemente, sua consciência se modifica, visto que a mesma se desenvolve a partir das vivências do ser humano. Conforme se modificaram os meios de produção material, os homens foram assumindo papéis sociais diferentes: uns assumiram o papel de capitalista que explora a força de produção para ter lucros e outros o de operários assalariados que vendem sua força de trabalho ao capitalista em um sistema alienante. Assim, os operários se veem obrigados a trabalhar para o capitalista em troca de um salário, pois precisam de dinheiro para sustentar a família. Partindo disso, o trabalho assume um papel alienante com relação ao desenvolvimento da consciência dos homens.

A educação tem o papel de formar os alunos para o exercício da cidadania, para que sejam capa- zes de agir ativamente para modificar sua condição econômica e social. Assim, a educação não pode se prender a métodos que levam à alienação dos alunos, mas sim deve desenvolver neles uma consciência que seja voltada à crítica do modelo de sociedade capitalista, onde poucos são privilegiados.

\section{Referências}

CARMO, Apolônio Abadio do. Deficiência física: a sociedade brasileira cria, "recupera" e discrimina. Brasília: Secretaria dos Desportos/PR, 1991.

CAZINI, Janaina. Projeto Vozes: Inovações tecnológicas sociais para inclusão digital de deficientes visuais. In: EPEGE Encontro Paranaense de Empreendedorismo dos Campos Gerais, 6, 2009. Ponta Grossa. Anais, mais...

CARTA ao Presidente da Província. Ano 1884. Arquivo Público do Paraná. Cod. 715.116. Coletado 05/06/2010.

CELIO, Reginaldo. A trajetória da equipe de coordenação de um fórum de famílias de alunos com deficiência a partir da sociodinâmica estabelecitos: outsides. Disponível em: http://www.uel.br/grupo-estudo/processoscivilizadores/. Acesso em: 10 jun. 2010.

ELIAS, Norbert; SCOTSON, John L. Os estabelecidos e os outsiders: sociologia das relações de poder a partir de uma pequena comunidade. Rio de Janeiro: Jorge Zahar, 2000. $213 p$. Zahar, 1994

A sociedade dos indivíduos. Rio de Janeiro: Jorge

FRASSON, Antonio Carlos. Atores sociais das ruas: esporte zero hora. In: SIMPÓSIO DE EDUCAÇÃO FÍSICA E DESPORTOS DO SUL DO BRASIL, 15, 2003. Ponta Grossa. Anais... Ponta Grossa, 2003.

FRASSON, Antonio Carlos; PIETROCHINSKI, Andrea; SCHULMEISTER, Clarice. Auditory Deficient People: His Educative and Social Inclusion by Norbert Elias. In: SIMPÓSIO INTERNACIONAL PROCESO CIVILIZADOR, 11, 2008, Buenos Aires. Anais... Buenos Aires, 2008.

INES- Instituto Nacional de Educação de Surdos. Disponível em: <http://www.ines.gov.br/>. Acesso em: 10 junho 2010.

JORNAL Folha de São Paulo (1988- 1998).

JORNAL Gazeta do Povo (1982 - 2001).

JORNAL O Correio (1974-1984).

JORNAL O Estado do Paraná (1974).

MIRANDA, Maria Rosa Pimentel Faria de. Informação, leitura e inclusão educacional e social nas Bibliotecas Braille de Campo Grande/MS: um estudo de caso. UNB/ UNIDERP, 2005. 
NERI, Marcelo Cortês, et al. Retratos da deficiência no Brasil (PCD). Rio de Janeiro: FGV/IBRE, CPS, 2003. 250p.

ONU. Normas sobre igualdade de oportunidades para pessoas com deficiência. Lisboa: Nações Unidas, 1995. p.23.

RELAÇÃO dos brasileiros cegos e surdos na comarca de Curityba. Ano 1870. Arquivo Público do Paraná. Cod. 340.190. Coletado em: 05/06/2010.

SIMÕES, José Luiz. Escola para as elites, cadeia para os vadios: relatos da imprensa piracicabana (1889-1930). Tese (doutorado) apresentada à Universidade Metodista de Piracicaba, São Paulo, 2005.

STRIJKER, Bertha Emilia; FRASSON, Antonio Carlos. Portadores de necessidades especiais: o esporte como fator de inclusão social. In: CONGRESSO INTERNACIONAL DE EDUCAÇÃO FÍSICA. Anais... Foz do Iguaçu, 2003.

SANTAROSA, Lucila M. C. Ambientes digitais virtuais: acessibilidade aos deficientes visuais - Revista RENOTE Novas Tecnologias na Educação CINTED-UFRGS, v.1, n.1, 2003. Disponível em: <http://seer.ufrgs.br/renote/article/ view/13637/7715>.

UNESCO. Inclusão digital e social de pessoas com deficiências: textos de referências para monitores de telecentros. Brasilia: UNESCO, 2007. 73p.

Recebido em: 17/11/2011.

Aprovado para publicação em: 10/04/2012 